\title{
Estimate the contribution of incubation parameters influence egg hatchability using multiple linear regression analysis
}

\author{
Mohamed H. Khalil, Mostafa K. Shebl, Mohamed A. Kosba, Karim El-Sabrout and Nesma Zaki \\ Department of Poultry Production, Faculty of Agriculture, Aflaton St., El-Shatby, \\ University of Alexandria, Alexandria, Egypt. \\ Corresponding author: Karim El-Sabrout, e-mail: kareem.badr@alexu.edu.eg, \\ MHK: mohamedhassankhalil@yahoo.com, MKS: mkshebl@yahoo.com, MAK: mkosba@hotmail.com, \\ NZ: nanazaki25@yahoo.com \\ Received: 27-05-2016, Accepted: 02-07-2016, Published online: 04-08-2016
}

doi: 10.14202/vetworld.2016.806-810 How to cite this article: Khalil MH, Shebl MK,Kosba MA, El-Sabrout K, Zaki N (2016) Estimate the contribution of incubation parameters influence egg hatchability using multiple linear regression analysis. Veterinary World, 9(8): 806-810.

\begin{abstract}
Aim: This research was conducted to determine the most affecting parameters on hatchability of indigenous and improved local chickens' eggs.

Materials and Methods: Five parameters were studied (fertility, early and late embryonic mortalities, shape index, egg weight, and egg weight loss) on four strains, namely Fayoumi, Alexandria, Matrouh, and Montazah. Multiple linear regression was performed on the studied parameters to determine the most influencing one on hatchability.

Results: The results showed significant differences in commercial and scientific hatchability among strains. Alexandria strain has the highest significant commercial hatchability (80.70\%). Regarding the studied strains, highly significant differences in hatching chick weight among strains were observed. Using multiple linear regression analysis, fertility made the greatest percent contribution $(71.31 \%)$ to hatchability, and the lowest percent contributions were made by shape index and egg weight loss.
\end{abstract}

Conclusion: A prediction of hatchability using multiple regression analysis could be a good tool to improve hatchability percentage in chickens.

Keywords: chickens, hatchability, multiple regression, path coefficient, prediction.

\section{Introduction}

Poultry production is a process which has an important role in bridging shortage of nutrition in developing countries. The hatchability of chicken eggs is one of the most important parameters for efficiency in hatchery practices. Heritability estimated for hatchability in chickens was low [1]. Numerous parameters have pronounced influence on the hatchability of chicken eggs and it is necessary to know the important parameters affecting hatchability success and its contribution.

In this study, we chose five incubation parameters which have a direct effect on hatchability. Statistical models can be used in prediction and helps to make the best decisions to approach maximum productivity in the poultry industry. Path coefficient analysis becomes successful tool which can be used in examining the possible causal linkage between statistical variables and for prediction [2].

The main objectives of this study were: (1) To determine the most studied incubation parameters

Copyright: Khalil, et al. Open Access. This article is distributed under the terms of the Creative Commons Attribution 4.0 International License (http://creativecommons.org/licenses/by/4.0/), which permits unrestricted use, distribution, and reproduction in any medium, provided you give appropriate credit to the original author(s) and the source, provide a link to the Creative Commons license, and indicate if changes were made. The Creative Commons Public Domain Dedication waiver (http://creativecommons.org/ publicdomain/zero/1.0/) applies to the data made available in this article, unless otherwise stated. affecting hatchability percentage; (2) to calculate the path coefficients of hatchability on the studied parameters; (3) to calculate the multiple regression coefficients of hatchability on the studied parameters. This study is very important to reach optimum hatchability percent of chicken eggs. Furthermore, the prediction of hatchability percent using multiple regression analysis is necessary to improve hatchability percentage in chickens.

\section{Materials and Methods \\ Ethical approval}

The approval from the Institutional Animal Ethics Committee to carry out this study was not required as no invasive technique was used.

\section{Study design}

This study was conducted at the Poultry Research Center, Alexandria University, Egypt. Four Egyptian chicken strains were used:

1. Alexandria (Alex): Obtained in 1958 by crossing between four strains of chickens (Fayoumi $\times$ Plymouth Rock $\times$ Rhode Island Red $\times$ White Leghorn) [3]

2. Fayoumi (Fay): Local Egyptian chicken strain

3. Matrouh (Mat): Obtained in 1974 by crossing between Doki-4 and white Leghorn [4]

4. Golden Montazah (G.M): Obtained in 1974 by crossing between Doki-4 and Rhode Island Red [5]. 
A total of 16 individual breeding pens have been used to produce chickens of the four strains (Alex, Fay, Mat, and G.M) used in this study. In each pen had one sire mated to 12 dams, with 4 replicates for each. Age of stock was 50 weeks. The experimental parents and hatching eggs exposed the same managerial treatments for all strains. The identified eggs were pedigreed for each dam through trap nesting. After that, the collected eggs were weighed and determined the egg shape index before set in an electric forced draft incubator. A total of 3144 eggs (Alex: 912, Fay: 683, Mat: 840, and G.M: 709) were collected in five hatches and taken during the period from December to January. During hatching, eggs were weighed at the $7^{\text {th }}$ and $18^{\text {th }}$ day of incubation using an electric digital scale to calculate the egg weight loss. On the $7^{\text {th }}$ and $18^{\text {th }}$ day of incubation, the eggs were candled and those with evidence of living embryos were transferred to the hatcher in individual pedigree boxes. On day 21, the hatched chicks were weighed and percentages of hatchability were calculated.

Hatchability percentages

- Hatchability of total eggs (Commercial) :

$$
\text { Hatchability } \%=\frac{\text { Number of chicks }}{\text { Number of set eggs }} \times 100
$$

- Hatchability of fertile eggs (Scientific):

$$
\text { Hatchability } \%=\frac{\text { Number of chicks }}{\text { Number of fertile eggs }} \times 100
$$

Hatching chick weight: Individual chick body weight

(g) at hatching time.

\section{Statistical analysis}

Data were analyzed using IBM SPSS Statistics for Windows, version 20.0 [6].

- Multiple linear regression was performed on the studied parameters to determine the most influencing parameters on hatchability. The model for the multiple linear regression was as follows:

$\mathrm{Y}=\mathrm{a}+\mathrm{b}_{1} \mathrm{X}_{1}+\mathrm{b}_{2} \mathrm{X}_{2}+\ldots \ldots+\mathrm{b}_{6} \mathrm{X}_{6}$

Where,

$\mathrm{Y}=$ Response variable (hatchability \%),

$\mathrm{a}=$ Intercept,

$\mathrm{b}=$ Partial regression coefficient,

$\mathrm{X}=$ Independent variables (shape index, egg weight, early dead, late dead, egg weight loss, and fertility).

- Path coefficient: Standardized partial of regression coefficients were calculated. It was to involve a direct comparison of values to reflect the importance relative of independent variables $(\mathrm{X})$ to explain variation in the dependent variable (Y). The path coefficient from an explanatory variable (X) to a response variable (Y) as described by Mendes et al. [7] is shown below:

$\mathrm{P}_{\mathrm{Y} . \mathrm{X}_{\mathrm{i}}}=\mathrm{b}_{\mathrm{i}} \frac{\mathrm{S}_{\mathrm{X}_{\mathrm{i}}}}{\mathrm{S}_{\mathrm{Y}}}$

Where,
$\mathrm{P}_{\mathrm{Y} . \mathrm{X}_{\mathrm{i}}}=$ Path coefficient from $\mathrm{X}_{\mathrm{i}}$ to $\mathrm{Y}(\mathrm{i}=$ parameters affecting),

$b_{i}=$ Partial regression coefficient,

$\mathrm{S}_{\mathrm{X}_{\mathrm{i}}}=$ Standard deviation of $\mathrm{X}_{\mathrm{i}}$

$\mathrm{S}_{\mathrm{Y}}=$ Standard deviation of $\mathrm{Y}$.

- The significance of each path coefficient in the multiple linear regression model was tested by t-test.

- Coefficient of determination $\left(\mathrm{R}^{2}\right)$ was calculated as follows:

$$
\mathrm{R}^{2}=\frac{\text { Sum squares due to regression }}{\text { Total sum squares }}
$$

\section{Results and Discussion}

Regarding the studied strains (Table-1), significant differences in commercial and scientific hatchability among strains were observed. However, Alexandria strain has the highest significant $(\mathrm{p} \leq 0.01)$ commercial hatchability $(80.70 \%)$, over that for Matrouh (64.68\%), Fayoumi (57.41\%), and Montazah $(45.26 \%)$ strains. In respect of scientific hatchability percentages, Alexandria, Montazah and Fayoumi strains have statistically equal significant $(\mathrm{p} \leq 0.05)$ values $(92.59,87.69$ and $87.57 \%$, respectively), over that for Matrouh strain (70.69\%).

According to the indicative performance records for scientific hatchability ( $>93 \%$ excellent, $>90 \%$ very good, $>87 \%$ good, $>83 \%$ average, and $<83 \%$ poor) [8], the assessment of the percentages of this parameter obtained here in this study (Table-1) according to the previous categories indicated that Alexandria strain has very good hatchability, Fayoumi, and Montazah have good hatchability, while Matrouh has poor hatchability. The significant hatchability between strains may be due to fertility.

Alsobayel and Albadry [9] reported that hatchability percentages were significantly affected by breed. Allanah et al. [10] revealed that hatchability was the highest in the improved and native chicken strains, followed by the exotic strains which recorded the least percentage hatchability.

\begin{tabular}{|c|c|c|c|c|c|}
\hline \multirow[t]{2}{*}{ Strains } & \multirow[t]{2}{*}{$\mathbf{N}$} & \multicolumn{2}{|c|}{$\begin{array}{c}\text { Commercial } \\
\text { hatchability (\%) }\end{array}$} & \multicolumn{2}{|c|}{$\begin{array}{c}\text { Scientific } \\
\text { hatchability }(\%)\end{array}$} \\
\hline & & $\overline{\mathbf{x}}^{1}$ & SE$^{2}$ & $\overline{\mathbf{X}}^{1}$ & SE $^{2}$ \\
\hline Alexandria & 11 & $80.70^{A}$ & 2.78 & $92.59^{A}$ & 3.57 \\
\hline Fayoumi & 12 & $57.41^{c}$ & 3.42 & $87.57^{A}$ & 4.43 \\
\hline Matrouh & 6 & $64.68^{\mathrm{B}}$ & 5.11 & $70.69^{B}$ & 5.17 \\
\hline Montazah & 12 & $45.26^{D}$ & 5.16 & $87.69^{A}$ & 5.71 \\
\hline Factor & & $\mathrm{p}$ value & Significant & $\mathrm{p}$ value & Significant \\
\hline Strains & & 0.002 & $* *$ & 0.048 & * \\
\hline
\end{tabular}

Table-1: Means and standard error $\left(\overline{\mathrm{X}}^{1} \pm \mathrm{SE}^{2}\right)$ of hatchability (\%) by strain along with test of significance.

${ }^{1}$ Means of actual data, ${ }^{2} \mathrm{SE}$ for transformed data.

$* p \leq 0.05 ; * * p \leq 0.01$, Means having different letter for each character are significantly different $(p \leq 0.05)$.

SE: Standard error 
In addition, highly significant differences in hatching chick weight among strains were observed. Alexandria, Montazah, and Matrouh strains have statistically equal significant hatching chick weight (37.54, 37.78, and $36.64 \mathrm{~g}$, respectively), while Fayoumi was $33.11 \mathrm{~g}$. The significant difference among strains may be due to the significant difference in egg weight.

\section{Establishment of preliminary and optimized multiple regression equations}

\section{Preliminary multiple regression equation}

Multiple linear regression analysis gives the amount by which the dependent variable (hatchability $\%$ ) increases when one independent variable (studied parameters) is changed by one unit and all the other independent variables are held constant. In particular, the value of the partial coefficient for one independent variable will vary, depending on the other independent variables included in the regression equation. Multiple regression equation of hatchability (\%) on the parameters studied was as follows (Table-2 and Figure-1).

Hatchability $=55.42-0.29 \mathrm{SI}+0.42 \mathrm{EW}-1.14$ $\mathrm{ED}-0.66 \mathrm{LD}-0.99 \mathrm{EL}+0.87 \mathrm{~F}$

Where, $\mathrm{SI}=$ Shape index, EW = Egg weight, ED $=$ Early dead, $\mathrm{LD}=$ Late dead, $\mathrm{EL}=$ Egg wt. loss, and $\mathrm{F}=$ Fertility.

Partial regression coefficients are the slope coefficients (b's) in a multiple regression model. The partial regression coefficients were $-0.29,0.42,-1.14,-0.66$,

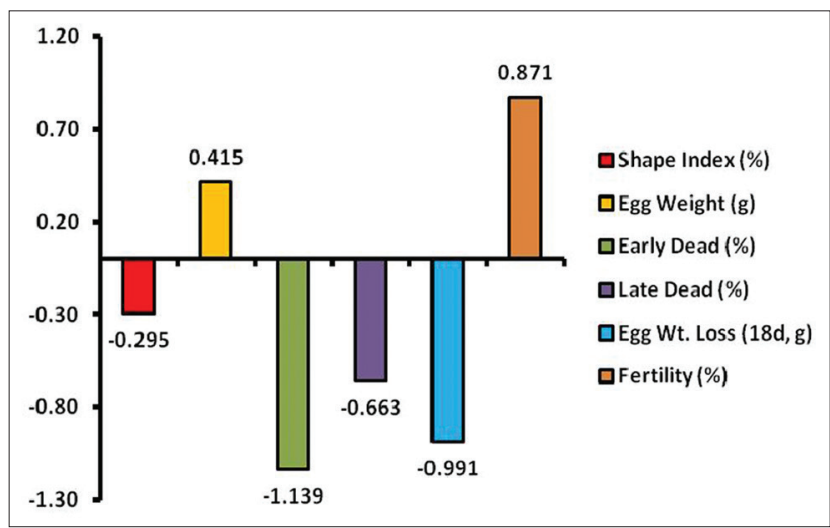

Figure-1: Multiple regression of hatchability on the studied parameters.
-0.99 , and $0.87 \%$ for these independent variables (SI, EW, ED, LD, EL, and F, respectively) (Table-2).

This equation implies that one unit decrease in these parameters (SI, ED, LD, and EL) will increase hatchability by $0.29 \%, 1.14 \%, 0.66 \%$, and $0.99 \%$, respectively, within the minimum and maximum values of these parameters, and all the other independent variables are held constant. On the other hand, the independent variables (EW and F) increase with one unit, hatchability will increase by $0.42 \%$ and $0.87 \%$, respectively, within the minimum and maximum values of these parameters; all the other independent variables are held constant (Table-2). The independent variables (EW, ED, LD, and F) had a significant effect on hatchability. However, the rest independent variables studied (SI and EL) were not significant.

Egg weight loss did not significantly affect hatchability. This may due to the water lost from eggs was within the normal lost during incubation. Egg weight loss ranged from $10.03 \%$ to $10.96 \%$ by strain in this study. Ha [11] cleared that the best hatchability is obtained with poultry species when eggs lose $12 \%$ of their fresh weight from time of lay to time the embryo opens the shell, and hatchability decreases for eggs losing $<10 \%$ or $>15 \%$ of their fresh egg weight. In addition, this may be attributed to reflection of functional porosity of the shell and the initial mass of each egg. Abiola et al. [12] reported that egg weight loss may affect hatchability through the proportion of pore areas and pore diameter regardless of the size of egg.

\section{Path coefficients}

The path analysis has as intermediary calculation the normal equation system such as multiple regression. Path coefficients of hatchability on the independent parameters studied are presented in Table-2. The equation of path coefficient implies that one unit decrease in standard deviation of SI, ED, LD, EL results in an increase of hatchability equal to 0.023 , $0.157,0.085$ and 0.041 , respectively. However, EW and $\mathrm{F}$ increase with one unit; hatchability will increase by 0.069 and 0.932 , respectively.

\section{Contribution percentage of studied parameters}

Fertility made the greatest percent contribution $(71.31 \%)$ to hatchability in chickens (Table-2),

Table-2: Multiple regression, path coefficients, and its contribution of commercial hatchability (\%) on the studied parameters.

\begin{tabular}{lccccc}
\hline $\begin{array}{l}\text { Commercial } \\
\text { hatchability (\%) }\end{array}$ & Regression coefficient & Path coefficient & Contribution (\%) & p value & Significant \\
\hline (Constant) & 55.42 & & & & \\
Shape index (\%) & -0.295 & -0.023 & 1.76 & 0.257 & NS \\
Egg weight (g) & 0.415 & 0.069 & 5.28 & 0.001 & $* * *$ \\
Early dead (\%) & -1.139 & -0.157 & 12.01 & 0.000 & $* * * *$ \\
Late dead (\%) & -0.663 & -0.085 & 6.5 & 0.000 & $* * * *$ \\
Egg weight loss (18 d,g) & -0.991 & -0.041 & 71.31 & 0.053 & NS \\
Fertility (\%) & 0.871 & 0.932 & & & $* * * *$ \\
$\mathrm{R}^{2}$ & 0.86 & & & & \\
\hline
\end{tabular}

$* * * \mathrm{p} \leq 0.001, * * * * \mathrm{p} \leq 0.0001 . \mathrm{NS}=$ Not significant 
followed by early embryo dead by $12.01 \%$, late embryo dead by $6.50 \%$ and egg weight by $5.28 \%$. The lowest percent contributions were made by egg weight loss and shape index by $3.14 \%$ and $1.76 \%$, respectively (Table-2 and Figure-2).

\section{Optimized multiple regression equation}

Because the partial regression coefficients of some characters studied (shape index and egg weight loss) were statistically not significant, thus these characters were expunged from the regression model to obtain a much more simplified equation. After the removal of the redundant variables from the initial regression equations, the optimized but much simplified equation model (Table-3) with their coefficient of determination was:

$$
\begin{aligned}
\text { Hatchability }= & 18.67+0.34 \mathrm{EW}-1.14 \mathrm{ED} \\
& -0.68 \mathrm{LD}+0.87 \mathrm{~F}
\end{aligned}
$$

Where $(E W=$ Egg weight, $E D=$ Early dead, LD $=$ Late dead, and $\mathrm{F}=$ Fertility).

This equation implies that one unit increase in these parameters (EW and F) will increase hatchability by $0.34 \%$ and $0.87 \%$, respectively, within the minimum and maximum values of these parameters; and all the other independent variables are held constant. On the other hand, ED and LD if decreased with one unit, hatchability will increase by $0.1 .14 \%$ and $0.68 \%$, respectively (Table-3 and Figure-3).

Similar results were reported by Wolanski et al. [13] and Alabi et al. [14] in chickens. They reported that egg weight was effective on hatchability of fertile eggs. The medium and large-sized eggs had significantly higher hatchability values than smallsized eggs. In addition, they found that medium-sized eggs had significantly higher hatchability than both small and large-sized eggs. Quadratic regression analysis revived that hatchability was optimized in eggs of Potchefstroom Koekoek chickens weighting approximately $51 \mathrm{~g}\left(\mathrm{r}^{2}=100\right)$. If performance (e.g., weight gain, live weight, feed intake, feed conversion ratio, mortality) is of high importance, large eggs can be considered [14]. Moreover, De Witt and Schwalbach [15] found that large-size eggs recorded to have higher hatchability percent in Rhode Island Red and New Hampshire chickens. In addition, working on three rural chickens' breeds, Abdul Rashid et al. [16] found that large-sized eggs had higher hatchability than small sized eggs. Moreover, the categories of egg weight significantly affected mortality of embryos.
The highest early and late embryonic mortalities were observed in small-size egg weight followed by that of medium and large-size egg weight. Higher mid embryonic mortality was observed in small and large egg weight categories than in medium ones [17].

On the other hand, Ramaphala [18] found no differences between different egg sizes were detected with hatchability percentage and percentage hatch of fertile in Cobb 500 broiler chickens breeder eggs.

The increase of early and late embryonic mortalities of eggs caused a reduction in hatchability. The findings of Elibol and Brake [19] supported these results. They indicated that fertile hatchability decreased due to increased percentage early and late embryonic mortalities of broiler eggs.

\section{Path coefficients}

The equation of path coefficient (Table-3) implies that one unit increase in standard deviation of

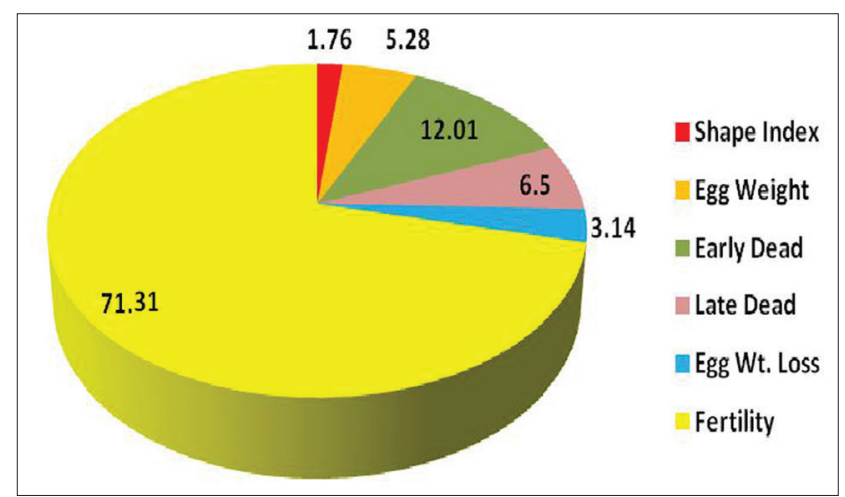

Figure-2: The contribution of the studied parameters on hatchability.

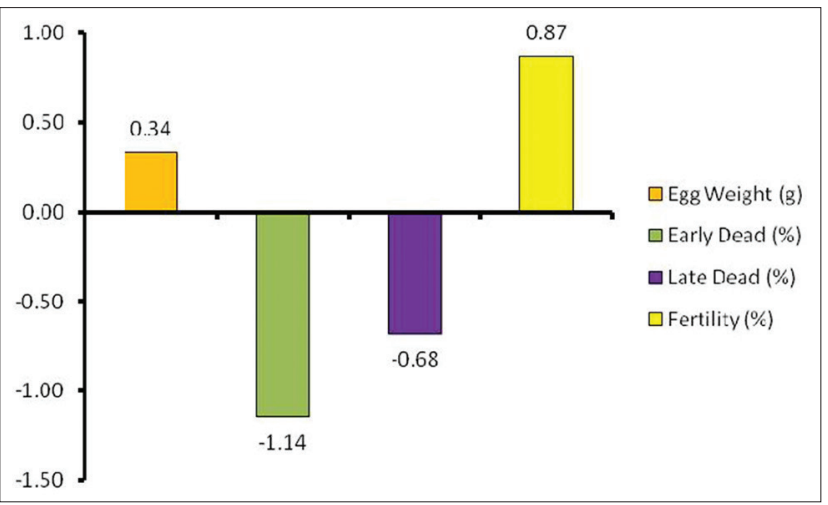

Figure-3: Multiple regression of hatchability on the significant studied parameters.

Table-3: Multiple regression, path coefficients, and its contribution of commercial hatchability (\%) on the significant

\begin{tabular}{|c|c|c|c|c|c|}
\hline Parameters & Regression coefficient & Path coefficient & Contribution (\%) & p value & Significant \\
\hline (Constant) & 18.678 & & & & \\
\hline Egg weight (g) & 0.336 & 0.056 & 4.55 & 0.007 & $* *$ \\
\hline Early dead (\%) & -1.143 & -0.158 & 12.84 & 0.000 & $* * * *$ \\
\hline Late dead (\%) & -0.679 & -0.087 & 7.07 & 0.000 & $* * * *$ \\
\hline Fertility (\%) & 0.869 & 0.930 & 75.55 & 0.000 & $* * * *$ \\
\hline $\mathrm{R}^{2}$ & 0.86 & & & & \\
\hline
\end{tabular}
studied parameters.

$* * \mathrm{p} \leq 0.01, * * * * \mathrm{p} \leq 0.0001$ 


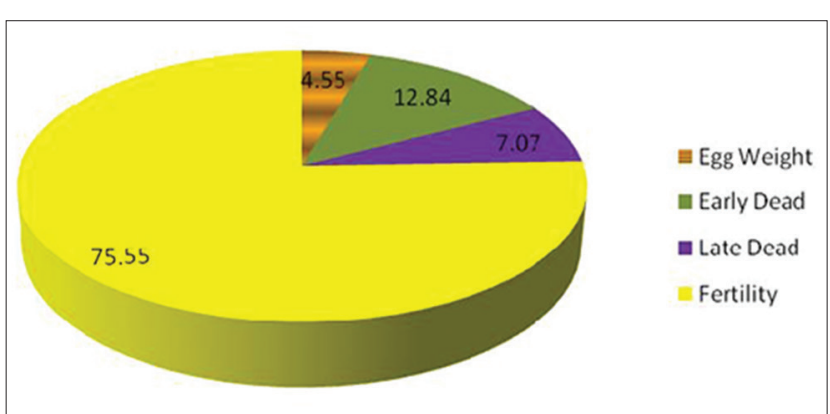

Figure-4: The contribution of significant studied parameters on hatchability.

EW and $\mathrm{F}$ results in an increase of hatchability equal to 0.056 and 0.93 , respectively. However, ED and LD decrease with one unit in standard deviation, hatchability will increase by 0.158 and 0.087 , respectively.

\section{Contribution percentage of studied parameters}

Fertility made the greatest percent contribution $(75.55 \%)$ to hatchability in chickens (Table-3), followed by early embryo dead by $12.84 \%$, late embryo dead by $7.07 \%$, and egg weight by $4.55 \%$ (Table- 3 and Figure-4).

\section{Conclusion}

The prediction of hatchability percent using multiple regression analysis could be a good method for estimating the performance and breeding value of chickens. Furthermore, the relationships existing between hatchability and other parameters studied may be useful in breeding plan, thereby providing a basis for the genetic manipulation and improvement of the native stock.

\section{Authors' Contributions}

MHK, MKS and MAK carried out the experiment design, statistical analysis and data interpretation. KE participated in practical work and wrote the manuscript. MHK and KE had the primary responsibility for the content of the manuscript. All authors read and approved this manuscript.

\section{Acknowledgments}

The authors are grateful to the Director of Poultry Research Center and Head, Department of Poultry Production at Alexandria University for their technical support during conducting this work.

\section{Competing Interests} interests.

The authors declare that they have no competing

\section{References}

1. Sapp, R.L., Rekaya, R., Misztal, I. and Wing, T. (2004) Male and female fertility and hatchability in chickens: A longitudinal mixed model approach. Poult. Sci., 83: 1253-1259.

2. Udensi, O. and Ikpeme, E.V. (2012) Correlation and path coefficient analyses of Seed yield and its contributing traits in Cajanus cajan (L.) Millsp. Am. J. Exp. Agric., 2(3): 351-358.

3. Kosba, M.A. (1966) Analysis of an Experiment on Selection for Economic Traits in Chickens. MSc Thesis. Alexandria University, EG.

4. Mahmoud, T.H., Madkour, Y.H., Sayed, I.F. and Harirah, K.M. (1974a) The Golden Montazah a new variety of chickens. Agric. Res. Rev., 52: 51-60.

5. Mahmoud, T.H., Madkour, Y.H., Sayed, I.F. and Harirah, K.M. (1974b) Matrouh a new breed of chickens. Agric. Res. Rev., 52: 87-96.

6. SPSS. Statistics for Windows, Version 20.0, Released 2011. Armonk, NY: IBM Corporation.

7. Mendes, M., Karabayir, A. and Pala, A. (2005) Path analysis of the relationship between various body measures and live weight of American Bronze turkeys under three different lighting programs. Tar. Bilim. Der., 11: 184-188.

8. CEVA, Santé Animale. (2007) Embryo diagnosis an important tool to help the hatchery manager. Avian Business Unit, Issue No.14. CEVA Santé Animale, Libourne, France.

9. Alsobayel, A.A. and Albadry, M.A. (2012) Effect of age and sex ratio on fertility and hatchability of Baladi and leghorn laying hens. J. Anim. Plant Sci., 22: 15-19.

10. Allanah, T.O., Okonkwo, J.C. and Omeje, S.I. (2014) Fertility and hatchability characterization of three strains of egg type chickens. Sci. J. Biol. Sci., 3: 59-68.

11. Ha, D.N. (2013) A Study of Egg Quality and Incubation Parameters in Six Breeds of Local Chickens. M.Sc. Thesis, National Chung-Hsing University, TW.

12. Abiola, S.S., Meshioye, O.O., Oyerinde, B.O. and Bamgbose, M.A. (2008) Effect of egg size on hatchability of broiler chicks. Arch. Zootech., 57: 83-86.

13. Wolanski, N.J., Renema, R.A., Robinson, F.E., Carney, V.L. and Fencher, B.I. (2007) Relationships among egg characteristics, chick measuements, and early growth traits in ten broiler breeder Strains. Poult. Sci., 86: 1784-1792.

14. Alabi, O.J., Ng'ambi, J.W. and Norris, D. (2012) Effect of egg weight on physical egg parameters and hatchability of indigenous Venda chickens. Asian J. Anim. Vet. Adv., 7: $166-172$

15. De Witt, F. and Schwalbach, L.M. (2004) The effect of egg weight on the hatchability and growth performance of New Hampshire and Rhode Island Red chicks. S. Afr. J. Anim. Sci., 34: 62-64.

16. Abdul Rashid, S.H., Abbas, G., Amer, M.Y., Khan, M.J. and Iftikhar, N. (2013) Effect of egg weight on hatchability and hatchling weight in fayoumi, desi and crossbred (Rhode Island Red X Fayoumi) chickens. Vet. World, 6(9): 592-595.

17. Ishaq, H.M., Akram, M., Baber, M.E., Jatoi, A.S., Sahota, A.W., Javed, K., Mehmood, S., Hussain, J. and Husnain, F. (2014) Embryonic mortality in Cobb broiler strain with three egg weight and storage periods at four production phases. J. Anim. Plant Sci., 24: 1623-1628.

18. Ramaphala, O. (2013) Effect of Egg Weight on Hatchability and Chick Hatch-Weight of Cobb 500 Broiler Chickens. M.Sc. Thesis. University of South Africa, ZA.

19. Elibol, O. and Brake, J. (2008) Weight and position relative to incubator fan on broiler hatchability and chick quality. Poult. Sci., 87: 1913-1918. 